\title{
The Field of Near-Death Studies Through 2001: An Analysis of the Periodical Literature
}

\author{
Janice Miner Holden, Ed.D., LPC, LMFT, NCC, CST \\ University of North Texas \\ Rozan Christian, Ph.D. \\ Dallas, TX
}

\begin{abstract}
Since 1975, when Raymond Moody coined the term "near-death experience" (NDE), numerous articles have been published addressing NDEs and related phenomena. To make that literature accessible to researchers, the International Association for Near-Death Studies published an Index (2005) on CD-ROM in which the authors used 135 near-death-related topics to analyze more than 800 articles, including comprehensive coverage of more than 600 scholarly articles, published through 2001. Upon completion, the authors realized the Index revealed interesting descriptive data profiling the scholarly literature of the first quarter century of the field of near-death studies. Those data are presented in this article, including findings regarding dates, venues, authors, and topics of scholarly publications. The article concludes with a brief discussion of underaddressed topics in the field and of plans for an updated comprehensive index of all periodical publications, both scholarly and nonscholarly, in 2006 to commemorate the first 30 years of the formal field of near-death studies.
\end{abstract}

KEY WORDS: near-death experiences; literature review; journal information; audiovisual communications media; interdisciplinary research.

Janice Miner Holden, Ed.D., LPC, LMFT, NCC, CST, is professor of counseling and coordinator of the counseling program at the University of North Texas. She serves currently as President of the International Association for Near-Death Studies. Rozan Christian, $\mathrm{Ph} . \mathrm{D}$., recently completed her doctorate in counseling at the University of North Texas and is currently in the private practice of counseling in Dallas, TX, providing general counseling for a variety of concerns and specializing in grief counseling. Reprint requests should be addressed to Dr. Holden at the College of Education, University of North Texas, P.O. Box 310829, Denton, TX 76203-0829; e-mail: holden@unt.edu. 
Since 1975, when Raymond Moody coined the term "near-death experience" in his classic book, Life after Life, numerous authors have published periodical literature on near-death and related experiences. To provide researchers with easy and meaningful access to that literature, a team at the University of North Texas, the authors of this article, created two Compact Disks-Read Only Memory (CD-ROMs): Near-Death Experiences Research Bibliography, Part 1 (hereafter called Bibliography) (International Association for Near-Death Studies [IANDS], 2002), and Near-Death Experiences: Index to the Periodical Literature through 2001 (hereafter called Index) (IANDS, 2005c). The Bibliography indexed the 263 articles from Anabiosis: The Journal of Near-Death Studies (1981-1987) (hereafter called Anabiosis) and the Journal of Near-Death Studies (1987-present) published from the Journal's inception through 2001. The Index included those articles plus all other scholarly articles identified through an exhaustive search of the scholarly periodical literature published through 2001 , including primarily refereed journal articles along with a few other types, such as newsletter articles published by scholarly organizations. It also included many nonscholarly articles identified through a convenience search of the nonscholarly periodical literature during that same time period. The result was a total of more than 800 articles addressing near-death and related experiences: 703 scholarly and 123 nonscholarly.

For both CDs, we analyzed each article by 135 near-death-related topics. Each article citation appeared in the CD with all the topics it addressed listed beneath it, along with 100 percent of article abstracts in the Bibliography and 98 percent in the Index. In addition, each topic appeared with a listing of citations of all articles that addressed that topic. With the inclusion of a search capability, the CD enabled a user to create a comprehensive custom list of articles relevant to the research topic at hand. For those who did not have access to reprints, the CDs included the means for the user to purchase one copy of each desired reprint through the IANDS office in Connecticut.

Although we undertook development of these CDs to assist and encourage scholarly research into near-death experiences, once we completed the Index, we discovered that it revealed interesting descriptive data about the first 25 years of research and theory into near-death and related experiences. In this article, we will describe the process we used to create the CDs and will report the results of an analysis of the Index. 


\section{Method}

The inspiration for the CDs came from a publication by one of our colleagues on the University of North Texas (UNT) counseling program faculty. Garry Landreth and associates had published an original and an updated volume of the book, The World of Play Therapy Literature, in which he and a team of graduate students indexed all refereed journal articles organized into 76 topics related to play therapy (Landreth, Homeyer, Bratton, and Kale, 1995). Through Landreth's Center for Play Therapy at UNT, someone researching play therapy could find a reprint of each of these articles, along with every book that had been published on play therapy. In 2000 , we began imagining a similar resource for the field of near-death studies. We saw the first step to be the indexing of articles from the Journal of Near-Death Studies that we assumed at the time to be by far the single greatest publisher of near-death related, refereed articles, an assumption that was later confirmed, as will be discussed below.

\section{Creation of the Bibliography}

The senior author (J. M. H.) approached IANDS' Board of Directors, as well as her department chair, Michael Altekruse, who had access to university funds to support the project. The IANDS Board agreed to use funds from the organization's research account to match the funds that UNT allocated to the project. Between these two sources, she was able to hire Gary Boudreaux, a 4-D database developer, to create the list/order form for the CD, and Anneliese Fox, head of Fox Computer Systems and IANDS' office manager, to create the artwork for, and actually produce, the CD. In the end, UNT funded somewhat more than half of the $\$ 18,000$ that it cost to produce the Bibliography.

We began by making two photocopies of each article, beginning with the 1981 Volume 1, Number 1 of Anabiosis and ending with the 2001 Volume 19, Number 4 of the Journal of Near-Death Studies. One photocopy served as a working copy, the other as an archival copy that would be used as a master for reprint fulfillment.

Meanwhile, we consulted with Bruce Greyson at the University of Virginia Health System, Editor of Anabiosis and subsequently of the Journal of Near-Death Studies, to develop a preliminary list of topics pertaining to NDEs. Finalizing this list involved at least two challenges. One challenge was determining exactly how deeply to break topics down into subtopics. On the one hand, we hoped to 
achieve exclusivity or "narrowness" of focus that would be meaningful to a researcher seeking information on a specific topic. On the other hand, we hoped to avoid having so many topics that a researcher might feel awash in a mire of information while trying to determine all the topics relevant to a particular research focus.

Another challenge was determining parameters on the breadth of topics to be included. IANDS' literature and mission has included reference not only to NDEs proper but also to "similar" experiences (Kircher, Callanan, and IANDS Board of Directors, n.d.), "related" experiences (IANDS, 2005b), and "near-death-like" experiences (IANDS, 2005a). We considered whether to include topics on such phenomena as out-of-body experiences, after-death communication, precognition, and reincarnation, all of which have been included in NDE reports. As we delved into the articles, we modified the list that ultimately included 135 topics. Examples of topics appear in Table 3. A compete list of topics is available at http://iands.org/bibcd_topics.html.

At the time that the team undertook the project, the senior author (J. $M$. H.) had been active in the field of near-death studies for 15 years, whereas the junior author (R. C.) was new to the field. To establish some semblance of interrater reliability on article analysis, we began by each reading the same article independently, then comparing notes as to which topics each reader had identified. After a few articles, we reached near-100 percent agreement on two articles in a row. At that point, one of us (R. C.) proceeded independently to read and analyze the remaining articles. In this process, we categorized only topics addressed in the main body of the article, not the literature review. We reasoned that any topics addressed in NDE-related sources cited in a literature review would be included when we acquired and analyzed the main bodies of those sources for the already-planned Index.

We then entered each citation using American Psychological Association (2001) format along with identified topics into ProCite Version 5 database software program. When we finished, ProCite produced two lists. In one list, each topic was listed followed by a list of citations, organized alphabetically by last name of first author, of all the articles that addressed that topic; this list comprised a section of the Bibliography entitled "Topics with Citations." In the other list, each citation appeared alphabetically by last name of first author, and every topic addressed within the cited article was listed under the citation. We acquired copyright permission from Kluwer Academic Publishers, then-publisher of the Journal of Near-Death Studies, to reprint the article abstracts in the Bibliography. Together, the latter listing and 
the abstracts comprised the Bibliography section entitled "Citations with Abstracts and Topics." In addition to these two sections, the CD included "Instructions for Using This CD," a "Topics Outline," a "Feedback Form," and a final section describing "Creation of This CD."

\section{Creation of the Index}

Creation of the second CD-ROM was easier to the extent that the topics list was fixed and we were accustomed to the process of using it to analyze article contents. It was more difficult, however, in that it involved determining the parameters of which articles to include, as well as identifying, acquiring article reprints from, and acquiring copyright permission to reprint abstracts from numerous publication venues.

As noted above, NDEs involve several phenomena that are addressed in vast bodies of literature in their own right. An example is out-of-body experiences. Potentially, any article addressing a related topic could be included in the Index, categorized under the topic, "Related Experiences." To keep the focus of the Index primarily on NDEs proper, we made a judgment call to include only what we considered "classic" articles addressing related phenomena. Examples include Wilder Penfield's (1955) "The role of the temporal cortex in certain psychical phenomena," Celia Green's (1967) "Ecsomatic experiences and related phenomena," Walter Pahnke's (1969) "The psychedelic mystical experience in the human encounter with death," Karlis Osis and Erlendur Haraldsson's (1977) "Deathbed observations by physicians and nurses: A cross-cultural survey," William Richards' (1978) "Mystical and archetypal experience of terminal patients in DPT-assisted psychotherapy," and Kathleen Noble's (1987) "Psychological health and the experience of transcendence." What we considered "classic" was our own subjective opinion based on our knowledge of the fields of transpersonal psychology in general and near-death studies in particular; other scholars at the helm of this project undoubtedly would have decided to handle differently this entire matter in general and/or the determination of which notexplicitly-NDE-related articles qualified as "classic" in particular.

To conduct a thorough search of the scholarly periodical literature on NDEs in sources other than Anabiosis and the Journal of NearDeath Studies, we took several steps. We began with Terry Basford's (1990) Near-Death Experiences: An Annotated Bibliography, noting every periodical citation. We also drew from Richard Bonenfant's (2005 inactive) Lazarus website, adding to our list any articles that 
had not appeared in Basford's listing. We conducted exhaustive searches of the PsycINFO database using keywords associated with NDEs, again adding any new citations. We then acquired reprints of each article on that cumulative list, some from UNT library holdings, many through interlibrary loan services. Our final step was to review the References page( $s$ ) of each of those articles and acquire the reprints of any cited articles that we did not already have, but that appeared possibly to address NDEs. The result was a total of 565 articles from sources other than Anabiosis and the Journal of NearDeath Studies: 442 scholarly and 123 nonscholarly.

Although our search for scholarly articles was intended to be exhaustive, our listing of nonscholarly articles was not. We included only those we happened to encounter in our search for scholarly publications and did not, for example, consult the Reader's Guide to Periodical Literature to maximize the comprehensiveness of our listing of nonscholarly resources. For this reason, we will focus for the remainder of this article on findings related only to the scholarly literature on NDEs.

Other graduate students, Kathy Oden and Lisa Forest, undertook the monumental process of acquiring copyright permission from each publisher of scholarly articles to reproduce the article abstract in the Index. Another graduate student, Chris Lorenc, spent one semester "cleaning up" the reprints that would be used for reprint request fulfillment, making sure they were complete, legible, and so on. Boudreaux and Fox served the same functions in the production of the Index as the Bibliography. Ultimately, the Index cost approximately $\$ 11,000$ to produce, with IANDS bearing approximately one-third of the cost and UNT subsidizing the remainder. Neither this figure nor the Bibliography figure include the senior author's (J. M. H.'s) investment of hundreds of hours in the production of the CDs, nor do they include the investment of considerable time by some graduate students who worked on the Index for course credit rather than pay; thus, both figures should be considered not to represent the cost of production if all work had been directly compensated monetarily.

\section{Patterns in the Field of Near-Death Studies Emerging from the Index}

As noted above, we attempted to include an exhaustive list of references to scholarly articles addressing NDEs - whether or not an 
author explicitly used the term "near-death experience" - but also included several articles on similar, related, or like experiences. An analysis of the listings revealed that, of the total 703 scholarly articles cited in the Index, 89 addressed only the topic "Related Experiences Not Otherwise Specified (NOS)," and an additional 43 addressed specific related experiences, such as unidentified flying object (UFO) experiences, but not any specifically NDE-related topic. Excluding these articles left 571 that addressed at least one explicitly NDErelated topic. We recognize that, despite our most earnest efforts, some articles addressing NDEs may be missing from this total. However, these $\mathbf{5 7 1}$ articles can certainly be considered to comprise a reasonably accurate representation of the body of scholarly periodical literature of the field of near-death studies through 2001. The following sections are written with reference to this body of work unless otherwise specified.

\section{Findings Related to Dates of Publication}

The distribution of scholarly NDE publications by year appears in Figure 1. Although the field of near-death studies can be thought to have formally begun with the coining of the term "near-death experience" by Raymond Moody in 1975, the Index revealed that scholarly literature on the phenomenon began much earlier. According to our findings, the earliest article to explicitly address the phenomenon of NDEs (though not by that name) was A. S. Wiltse's 1889 work, "A case of typhoid fever with subnormal temperature and pulse," which appeared in the Saint Louis Medical and Surgical Journal. Indeed, 40 articles addressing NDEs by no term or some other term were published prior to 1977 , when the first articles appeared making explicit reference to Moody's work. Thirteen of those 40 articles (33 percent) appeared in the 75-year period between 1889 and 1964; the remaining 27 appeared in the 12-year period between 1965 and 1976, indicating that NDEs were increasingly addressed in scholarly venues during the decade before Moody named and provided a consolidated description of the phenomenon. Nevertheless, as the distribution shows, Moody's work was truly seminal in that the scholarly periodical near-death literature burgeoned after its publication.

Prior to the inception in 1981 of Anabiosis, 103 scholarly articles had already appeared addressing NDEs. In the 20 years since its inception (1981 to 2001), 261 articles appeared in Anabiosis and its successor, the Journal of Near-Death Studies, compared to 207 articles from all other scholarly venues combined. Thus, Anabiosis and its successor, 


\section{Figure 1 \\ Scholarly Articles Addressing Near-Death Experiences, 1889-2001.}

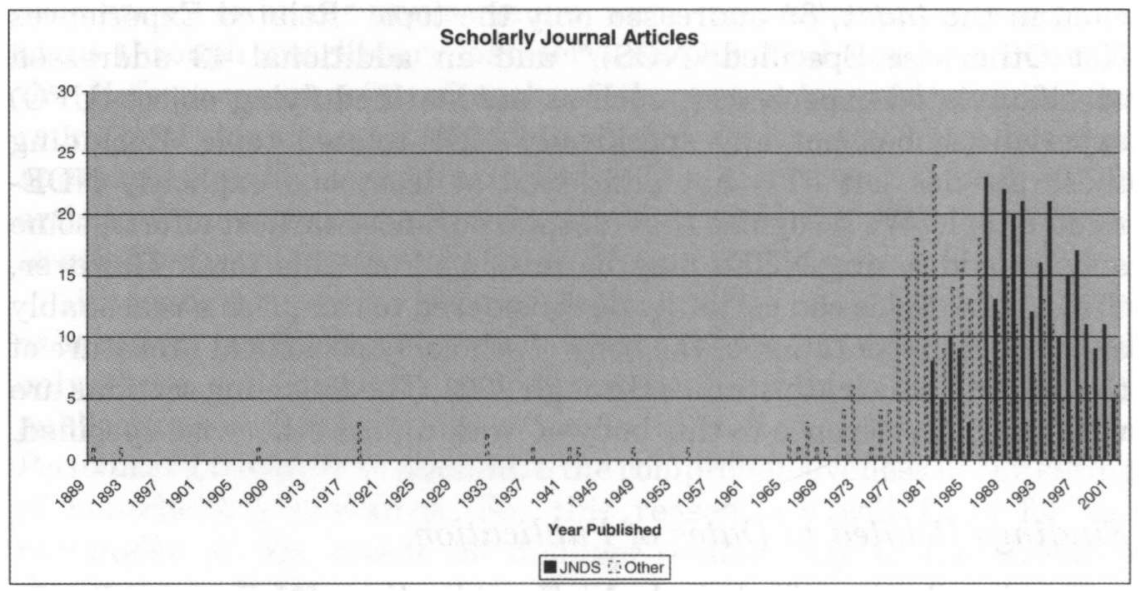

the Journal of Near-Death Studies has been a clear leader in the area of scholarly NDE-related periodical literature in quantity of publications.

\section{Findings Related to Scholarly Publication Venues}

A total of 124 scholarly periodical venues have published articles addressing near-death experiences. The titles of the top 30 venues and their corresponding number of NDE-related articles appear in Table 1. In addition to these 30 periodicals that published 3 or more articles on NDEs and related topics, 14 other scholarly periodicals published 2 articles each and an additional 80 periodicals published 1 article each.

Not surprisingly, 11 of the top 12 scholarly venues other than Anabiosis and the Journal of Near-Death Studies that published 6 or more articles on NDEs represented the fields of parapsychology research (4 journals), death studies ( 3 journals), medicine ( 2 journals), religion and health ( 1 journal), and transpersonal psychology ( 1 journal). More surprising to us was the finding that the third highest of those 11 represented the field of neuropsychiatric pathology, the Journal of Nervous and Mental Disease - surprising because NDEs have so consistently been found not to be associated with "nervous and mental disease" (Greyson, 1983, 1997, 2000). 


\section{Table 1}

\section{Scholarly Publication Venues Ranked by Number of Articles Addressing NDEs Through 2001}

\begin{tabular}{|c|c|c|}
\hline Rank & $\begin{array}{l}\text { Number } \\
\text { of Articles }\end{array}$ & Periodical \\
\hline 1 & 261 & $\begin{array}{l}\text { Anabiosis (1981-87)/Journal of Near-Death } \\
\quad \text { Studies }(1987-2001)\end{array}$ \\
\hline 2 & 22 & Omega \\
\hline 3 & 20 & $\begin{array}{l}\text { Journal of the American Society for } \\
\text { Psychical Research }\end{array}$ \\
\hline 4 & 19 & Journal of Nervous and Mental Disease \\
\hline 5 & 12 & Theta \\
\hline 6 & 11 & Parapsychology Review \\
\hline 7 & 10 & Lancet \\
\hline 8 & 9 & Journal of Religion and Health \\
\hline 9 & 8 & Journal of Transpersonal Psychology \\
\hline 10 & 6 & $\begin{array}{l}\text { Death Studies } \\
\text { Journal of Parapsychology } \\
\text { JAMA: Journal of the American } \\
\text { Medical Association } \\
\text { Research in Parapsychology }\end{array}$ \\
\hline 14 & 5 & $\begin{array}{l}\text { Death Education } \\
\text { Journal of Humanistic Psychology } \\
\text { Journal of Religion and Psychical Research } \\
\text { Journal of the Society for Psychical Research } \\
\quad \text { Psychiatry }\end{array}$ \\
\hline 19 & 4 & $\begin{array}{l}\text { American Journal of Diseases of Children } \\
\text { American Journal of Nursing } \\
\text { American Journal of Psychiatry } \\
\text { Contemporary Psychology } \\
\text { Essence } \\
\text { ReVision }\end{array}$ \\
\hline 25 & 3 & $\begin{array}{l}\text { American Psychologist } \\
\text { Journal of Indian Psychology } \\
\text { Journal of Scientific Exploration } \\
\text { Mortality } \\
\text { Proceedings of the Society for } \\
\quad \text { Psychical Research } \\
\text { Psychological Reports }\end{array}$ \\
\hline
\end{tabular}




\section{Findings Related to Publication Authors}

One might expect Raymond Moody to have authored the first scholarly publication with the term "near-death experience" in the title. In fact, that distinction goes to Carolyn Spencer, whose 1976 article, entitled "The effect of near-death experience on death anxiety," appeared in the Journal of Undergraduate Psychological Research. An examination of the article revealed a further irony: that it was not actually about near-death experiences at all but, rather, about neardeath episodes - the circumstances of a close brush with death during a catastrophic auto accident; Spencer did not question survivors about their subjective experiences during the crises. Thus did Moody lose the distinction of the first scholarly article to include in its title the term he had coined. In 1977, he (Moody, 1977), Michael Sabom and Sarah Kreutziger (1977), and an anonymous author in the Parapsychology Review (Anonymous, 1977) published articles with the term in the titles, and it appeared regularly in titles thereafter.

Numerous authors have contributed to the scholarly body of literature on near-death experiences. Ideally, a determination of the "experts" in the field of near-death studies as revealed by sole- or firstauthorship of scholarly articles would involve an assessment of the number, currency, and importance of those publications. We could easily determine number and currency of articles from Index data; importance was another matter. For example, the only article by any of the authors Pim van Lommel, Ruud van Wees, Vincent Meyers, and Ingrid Elfferich (2001), in which they reported in Lancet the results of a 13-year prospective study of NDEs in 10 Dutch hospitals, is arguably more important to the field of near-death studies than even the combination of several articles by some authors with multiple publications. However, lacking a systematic means to assess the importance of various articles, we were left with the cruder indices of number and currency of scholarly publications. Based on these criteria, the top 25 experts in the field of near-death studies appear in Table 2.

Among these experts are several people who have retired, such as Kenneth Ring and Ian Stevenson, or have died, such as Scott Rogo, James Hyslop, and Karlis Osis. Thus, the number of experts still active and potentially contributing further to the field of near-death studies is a shorter list by at least one-fifth.

Perhaps noteworthy also is the absence of certain names from the list. In many cases, the absence was purely the result of where we set the parameters for the list. For example, Moody and P. M. H. Atwater, 
Table 2

Top 25 First or Sole Authors of Articles Addressing NDEs Through 2001, Ranked by Number and Currency of Articles

\begin{tabular}{|c|c|c|c|c|}
\hline Rank & $\begin{array}{l}\text { Number } \\
\text { of Articles }\end{array}$ & Author & $\begin{array}{c}\text { Most recent } \\
\text { Article }\end{array}$ & Rank \\
\hline 1 & 32 & Greyson, Bruce & 2001 & 1 \\
\hline 2 & 25 & Ring, Kenneth & 2000 & 2 \\
\hline 3 & 16 & Lundahl, Craig & 2001 & 1 \\
\hline 4 & 14 & Serdahely, William & 1996 & 6 \\
\hline 5 & 12 & Noyes, Russell & 1989 & 12 \\
\hline 6 & 11 & Sabom, Michael & 2000 & 2 \\
\hline 7 & 10 & Becker, Carl & 1995 & 7 \\
\hline \multirow[t]{3}{*}{8} & 9 & Blackmore, Susan & 1998 & 4 \\
\hline & & Grosso, Michael & 1991 & 10 \\
\hline & & Kellehear, Allan & 1994 & 8 \\
\hline \multirow[t]{4}{*}{11} & 8 & Greene, F. Gordon & 1999 & 3 \\
\hline & & Holden, Janice M. & 1996 & 6 \\
\hline & & Morse, Melvin & 1997 & 5 \\
\hline & & Stevenson, Ian & 1995 & 7 \\
\hline 15 & 7 & Rogo, D. Scott & 1984 & 13 \\
\hline 16 & 6 & Jansen, Karl & 2000 & 2 \\
\hline \multirow[t]{3}{*}{17} & 5 & Gabbard, Glen & 1991 & 10 \\
\hline & & Hyslop, James H. & 1918 & 15 \\
\hline & & Irwin, Harvey & 1993 & 9 \\
\hline \multirow[t]{6}{*}{20} & 4 & Alvarado, Carlos & 2001 & 1 \\
\hline & & Gibbs, John & 1999 & 3 \\
\hline & & Green, J. Timothy & 2001 & 1 \\
\hline & & Osis, Karlis & 1983 & 14 \\
\hline & & Siegel, Ronald & 1984 & 13 \\
\hline & & Sutherland, Cherie & 1990 & 11 \\
\hline
\end{tabular}

both of whom are well-known book authors in the field, are among the 11 sole- or first-authors who have published three scholarly articles addressing or related to NDEs.

Findings Related to Topics Addressed in Publications

A final focus of this article is an analysis of topics addressed in scholarly periodical publications on NDEs. Based on the entire listing of topics and articles, rather than only those that explicitly address 
NDEs, the top 10 and bottom 10 topics, along with number of articles addressing each topic, appear in Table 3.

The fact that the most frequently addressed topic is pleasurable emotions during NDEs might be considered good news for the field of near-death studies. By comparison, slightly fewer than half that number addressed distressing emotions.

Some questions also emerge from the "most frequent topics" list regarding "not otherwise specified" categories. What are these 156 "Related Experiences NOS" that, together, appeared second most frequent, but did not include NDE-like categories such as out-of-body experiences ( 90 articles), or the UFO category (10 articles)? And what is the nature of the encountered beings described in 135 articles that did not include deceased or living entities (98 articles) or spiritual entities (79 articles)? Such questions suggest that a further analysis and breakdown of these NOS categories might be indicated to make the Index more helpful to researchers.

Regarding the least-addressed topics, the fact that only one article addressed the topic of humor and NDEs indicates that scholars apparently consider NDEs to be no laughing matter! A further fact may truly be no laughing matter: that four of seven topics addressing religion and NDEs appeared in the least-addressed list. Whereas authors addressed Christianity other than Mormonism in 32 articles, Mormonism in 11 articles, and Buddhism in 13 articles, they addressed Hinduism, Judaism, indigenous religions, and Islam in fewer than 7 articles each. Perhaps most glaring is that Islam was addressed in only two. Clearly, the relationship of NDEs to religion, particularly other than Christianity and Buddhism, is a topic ripe for further research in the field of near-death studies.

\section{Summary}

In this article, the creators of the Near-Death Experiences: Index to the Periodical Literature through 2001 analyzed the contents of the Index to provide a particular kind of profile of the field of near-death studies. We are currently seeking funding to create the rext version during the spring of 2006, a version that will cover thoroughly both the scholarly and nonscholarly periodical literature through 2005. The data emerging from the new Index version will undoubtedly confirm some observations reported in this article and indicate the need for revision of others. 
Table 3

Most and Least Addressed NDE Topics in Scholarly Articles Through 2001, Ranked by Frequency

\begin{tabular}{|c|c|c|}
\hline Rank & $\begin{array}{l}\text { Number } \\
\text { of Articles }\end{array}$ & Topic \\
\hline \multicolumn{3}{|c|}{ Most addressed topics } \\
\hline 1 & 162 & Characteristics of NDEs - Emotions, Pleasurable \\
\hline 2 & 156 & Related Experiences NOS \\
\hline 3 & 153 & Methodology in NDE Research \\
\hline 4 & 151 & Characteristics of NDEs - Autoscopy, Out-of-Body \\
\hline 5 & 135 & $\begin{array}{l}\text { Characteristics of NDEs - Encountering } \\
\text { Beings NOS }\end{array}$ \\
\hline 6 & 125 & Explanations of NDEs - Psychological \\
\hline 7 & 120 & $\begin{array}{l}\text { Explanations of NDEs - Physiological, } \\
\text { Neurological, Brain }\end{array}$ \\
\hline 8 & 119 & Characteristics of NDEs - Light, Mystical \\
\hline 9 & 113 & Altered States and NDEs \\
\hline 10 & 112 & Afterlife, Belief in \\
\hline 11 & 110 & Disclosure of NDEs \\
\hline 12 & 105 & Characteristics of NDEs NOS \\
\hline 13 & 101 & Circumstances of NDEs - Illness \\
\hline 14 & 100 & Science and NDEs \\
\hline 15 & 98 & $\begin{array}{l}\text { Characteristics of NDEs - Encountering Beings, } \\
\text { Deceased-Living }\end{array}$ \\
\hline
\end{tabular}

Least addressed topics

Characteristics of NDErs - Socioeconomic Status

Religion and NDEs - Hinduism

122

Shamanism and NDEs

Characteristics of NDEs - Sensory, Smell

Famous People's NDEs

Hypnosis and NDEs

Religion and NDEs - Judaism

Spiritualism and NDEs

Circumstances of NDEs - Combat-Related

Religion and NDEs - Indigenous Cultures

Artificial Intelligence and NDEs

Disabilities and NDEs

Characteristics of NDErs - Psychic Abilities

Circumstances of NDEs - Non-chemically Induced Religion and NDEs - Islam Humor about NDEs 


\section{References}

American Psychological Association. (2001). Publication manual of the American Psychological Association (5 ${ }^{\text {th }}$ ed.). Washington, DC: American Psychological Association.

Anonymous. (1977). Research on near death experiences. Parapsychology Review, 9(2), 17.

Basford, T. K. (1990). Near-death experiences: An annotated bibliography. New York: Garland.

Bonenfant, R. (2005 inactive). Lazarus. Retrieved June 20, 2005, from http:/www. parapsychologylab.com/lazarus.htm

Green, C. E. (1967). Ecsomatic experiences and related phenomena. Journal of the Society for Psychical Research, 44, 111-131.

Greyson, B. (1983). The psychodynamics of near-death experiences. Journal of Nervous and Mental Disease, 171, 376-381.

Greyson, B. (1997). The near-death experience as a focus of clinical attention. Journal of Nervous and Mental Disease, 185, 327-334.

Greyson, B. (2000). Dissociation in people who have near-death experiences: Out of their bodies or out of their minds? Lancet, 355, 460-463.

International Association for Near-Death Studies. (2002). Near-death experiences research bibliography, Part I [CD-ROM]. East Windsor Hill, CT: International Association for Near-Death Studies.

International Association for Near-Death Studies. (2005a). About IANDS. Retrieved June 20, 2005, from http://iands.org/about.php

International Association for Near-Death Studies. (2005b). Education. Retrieved June 20, 2005, from http://iands.org/education.html

International Association for Near-Death Studies. (2005c). Near-death experiences: Index to the periodical literature through 2001 [CD-ROM]. East Windsor Hill, CT: International Association for Near-Death Studies.

Kircher, P. M., Callanan, M., and IANDS Board of Directors. (n.d.). Near-death experiences and nearing death awareness in the terminally ill. Retrieved June 20, 2005, from http://iands.org/terminally_ill.html

Landreth, G., Homeyer, L., Bratton, S., and Kale, A. (1995). The world of play therapy lit erature ( $2^{\text {nd }}$ ed.). Denton, TX: University of North Texas Center for Play Therapy Press.

Moody, R. A. (1975). Life after life. Covington, GA: Mockingbird Books.

Noble, K. D. (1987). Psychological health and the experience of transcendence. Counseling Psychologist, 15, 601-614.

Osis, K., and Haraldsson, E. (1977). Deathbed observations by physicians and nurses: A cross-cultural survey. Journal of the American Society for Psychical Research, 71, 237-259.

Pahnke, W. N. (1969). The psychedelic mystical experience in the human encounter with death. Harvard Theological Review, 62, 1-21.

Penfield, W. (1955). The role of the temporal cortex in certain psychical phenomena. Journal of Mental Science, 101, 451-465.

Richards, W. A. (1978). Mystical and archetypal experiences of terminal patients in DPT-assisted psychotherapy. Journal of Religion and Health, 17, 117-125.

Sabom, M. B., and Kreutziger, S. (1977). Near-death experiences. Journal of the Florida Medical Association, 64, 648-650.

Spencer, C. S. (1976). The effect of near-death experience on death anxiety. Journal of Undergraduate Psychological Research, 3, 21-25.

van Lommel, P., van Wees, R., Meyers, V., and Elfferich, I. (2001). Near-death experience in survivors of cardiac arrest: A prospective study in the Netherlands. Lancet, 358, 2039-2045.

Wiltse, A. S. (1889). A case of typhoid fever with subnormal temperature and pulse. Saint Louis Medical and Surgical Journal, 57, 355-364. 